\title{
Metadiscursive Distinction between Persian and English: An Analysis of Computer Engineering Research Articles
}

\author{
Gholam Reza Zarei \\ English Language Center, Isfahan University of Technology, Isfahan, 84156-83111, Iran \\ Email: grzarei@cc.iut.ac.ir \\ Sara Mansoori \\ Department of Teaching English, Islamic Najafabad Azad University, Najaf abad, Isfahan, Iran \\ Email: s-mansoori@iaun.ac.ir
}

\begin{abstract}
The study tried to discover disciplinary distinctions between Persian and English in the academic genre. The focus was on the use of metadiscourse in the discipline of computer engineering research articles across the two languages. The selected corpus was analyzed through the model suggested by Hyland and Tse (2004). The results demonstrated that the two languages are distinct in their use of metadiscourse in the discipline studied. It was found that Persian, unlike English, relied on interactive resources more. The disciplinary distinction indicates that Persian computer engineering provides more textual elements while English language values a reader responsible trend.
\end{abstract}

Index Terms—academic text, metadiscourse, English language, Persian Language, computer engineering

\section{INTRODUCTION}

Discourse conventions have been shown to characterize different genres, among which Research Articles have recently come under lots of investigations. Through these discursive means scientists can acquire concepts, norms, values and ideological underpinning of a particular discipline. In fact, scientists of different fields access not only the subject matter but also a specialized form of literacy through research articles. That is, they can acquire rhetorical and linguistic practices of a particular community, rendering them distinct from one another (Ballard \& Clanchy, 1991). One important discourse feature which characterizes academic communities is 'metadiscourse', through which writers of academic disciplines intrude into the texts and represent themselves and their readers in one way or another.

Metadiscourse which is a tool to organize the discourse, engage the audience, and signal the writers' attitudes has recently been considered as a part of academic rhetoric and understood to be influenced by the writers' writing culture. As a way to form a cohesive and coherent text and to increase its readability, metadiscourse also called selfreferentiality technique (Ventola and Mauranen, 1991) and pre-revealing feature or metamessage (Johns, 1997) affects the personal tone and rhetorical presentation of information in texts. Thus, the degree of writer or reader responsibility, the writer's reference to their own act of thinking, writing organization or readers' act of reading and understanding is indicated by metadiscourse elements. But a great care should be taken in using them. That is, a certain amount is needed for readers to make sense of the texts. There may be some conditions in which unnecessary use of metadiscourse elements causes text redundancy sense and verbosity and too little may leave readers disoriented and confused. Though metadiscourse dose not refer to what is primarily said about the subject, it is necessary in everything written. Metadiscourse providing text linear development is the language used when the writer refers to his or her own act of thinking and writing, to the structure of what he or she writes and more importantly to his or her readers' act of reading.

Metadiscourse represents those aspects of the texts which are largely independent of propositional content but which are unavoidably local and confidentially joined to particular contexts and sometimes to particular disciplines. Although differrent according to each academic discipline convention, metadiscourse is generally used to announce what writers will do in what follows, to list the parts or steps in the presentation, to express logical connections, to show the degree of writers' certainty, or to indicate their intentions. The writers' awareness of disciplines and languages specific use of metadiscourse elements is necessary to adopt their texts into a language and discipline's norms, values and ideologies and to express their meanings so that they seem credible and convincing. In this process, writing is viewed as a social engagement and reveals how writers of different disciplines and languages position themselves within their discourse to signal their attitudes towards propositional contents and the audiences.

Metadiscourse can be viewed from two perspectives, textual and interpersonal. It can be limited to text organizing features (textual features) which help readers process the text and interpret it consistently with their epistemological understanding and genre expectations. The second point of view, which seems more comprehensive, adds the 
interactive elements or interpersonal features to help express the writers' attitudes and sureness and increase the force and persuasiveness of the argument. This kind of metadiscourse helps adopt a kind of balance between informing and persuading. Thus many researchers found that argumentative writing and persuasive texts of different discourse lends itself to the use of interpersonal metadiscourse. (Williams, 1989).

Perez-Ltanada (2003) views textual and interpersonal metadiscourse from two convergent disciplines, cognitive and pragmatic. From the perspective of cognition, metadiscourse necessarily focuses on the processing of production and processes of speech. In particular, through textual metadiscourse listeners can reconstruct the organizing structure of the talk, identify the logical linkage of contents, process the flow of information more easily and activate those schemata involved in communication.

From the view of sociology and pragmatics, the focus is on the process of interaction between speakers and listeners or the speaker and his/her community. Accordingly, the interpersonal metadiscourse allows the audience to understand speakers' implicatures and presuppositions as well as speakers' stance while considering the social framework of speech act. As academic discourse seems to be a matter of how to do things with words or of knowing how to communicate successfully to other peers, the formal structure of discourse is very important and metadiscourse reifies both cognitive and pragmatic demands of academic communication.

It is shown that metadiscourse occurs within the realm of writing and its presence may be demonstrated by affixes, words, sentences, whole clauses and paragraphs. It can provide cues and indicators that both help readers proceed through text and influence readers' reception. Metadiscourse may be used as a tool to make differentiations between cultures. Texts are mentioned as one of the main means to understanding a culture (Mauranen, 2001) and considered as cultural products which represent relevant social relationship within the culture. From this perspective, English belongs to the category of writer responsible (Hinds, 1987) or low context cultures (Hall and Hall, 1990), charging the writer or speaker with the responsibility to make clear and well-organized statements and vesting mass of information in the explicit code, in comparison with French, Finnish and Polish belonging to the reader responsible (Mauranen, 1993; Duszak, 1994) or high context cultures where most of the information is already in the person and very little is in the coded, explicit, transmitted message (Hall and Hall, 1990).

\section{RELEVANT STUDIES}

Metadiscourse in academic genre has received significant attention as an important rhetorical aspect which could affect the communicative ability of those concerned. Metadiscourse has been studied in various contexts and texts, e.g., casual conversation (Schiffrin, 1980); school textbooks (Crismore, 1989); science popularization (Crismore \& Farnsworth, 1990); post-graduate dissertation (Bunton, 1999); Darwin's Origins of the Species(Crismore \& Farnsworth, 1989); company annual reports (Hyland, 1998b); introductory course books (Hyland, 1999); undergraduate textbooks (Hyland, 2000); slogans and headlines (Fuertes-Olivera et al., 2001); and metadiscourse in academic writing: a reappraisal (Hyland and Tse, 2004).

Due to the peculiarity of the metadiscursive elements, some of the studies have investigated it in different disciplines and languages, e.g., Finish-English economic texts (Mauranan, 1993), Spanish-English economic texts (Valero, 1996), a comparison of linguistics and medicine abstracts (Melander et al., 1997) and medicine, economics and linguistics in English, French and Norwegian (Breivega et al, 2002). Few of these studies on metadiscourse in different disciplines and languages are reviewed below:

As a case in point, Hyland (1999) investigated the use of metadiscourse in two corpora-textbooks and research articles in three disciplines-Biology, Applied Linguistics and Marketing. The results demonstrated that the applied linguistics texts comprised considerably more evidentials and relational markers; the biology authors favored hedges; and marketing textbooks had fewer evidentials and endophorics. Hyland showed that biology had the greatest variation in most categories of metadiscourse both across genres and disciplines. It was also indicated that marketing and applied linguistics texts were more consistent across genres and both contained large differences in hedges and connectives. There were also found significant genre discrepancies in the use of evidentials and person markers in marketing, and endophorics and relation markers in applied linguistics. In general, there were greater genre differences than disciplinary ones, and the textbooks had a propensity to show evidences of greater disciplinary diversity than the research articles.

Likewise, Dahl (2004) investigated two kinds of metadiscourse (locational and rhetorical metatext) in three disciplines (Linguistics, Economics and Medicine) across three languages (English, Norwegian and French). She stated that "economics displayed a somewhat higher frequency of the two types than did Linguistics for both English and Norwegian, while for French there was hardly any difference within these two disciplines; for all three languages medicine used far less metatext than the other two disciplines.' (p., 1818). Also, medicine made the least use of metatext and its texts were presented in a highly structured format: Introduction-Methodology-Results-Discussion (Swales, 1990). She concluded that economics and linguistics in English and Norwegian showed very similar patterns, using much more metatext than French; within medicine, all three languages displayed a uniform pattern of little metatext.

The use of metadiscourse in academic articles written in English by English and Norwegian native speakers across three disciplines (Sociology, Psychology and Philosophy) has also been studied by Blagojevic (2004). Regardless of the 
languages, Blagojevic noticed that Psychology writers were reluctant to use the plain ways to state or remind the readers of the parts of the material which followed or preceded. They also used less attitude markers, but philosophy writers made most of the direct comments. Blagojevic's study also showed that philosophy writers had a high degree of diversity in their writing, while psychology writers had the highest degree of standardization in writing and sociology writers were somewhere in between.

Hyland and Tse (2004) carried out a research on the use of metadiscourse in postgraduate dissertations in six disciplines: Applied linguistics, Public administration, Business Studies, Computer science, Electric engineering, and Biology. The results showed that the humanities and social science disciplines employed more metadiscourse than the non-humanities. The study showed the greater use of metadiscourse in the humanities and more inter-disciplinary balance of interactive metadiscourse but its higher proportion in the science dissertations. Also, the results indicated that boosters and engagement markers were almost equally distributed across disciplines, but hedges were over twice more common in the humanities and self-mentions almost four times more frequent. Transitions were more carefully used in the humanities, but emphatics were used more in the non-humanities especially in engineering. Although the use of evidentials, which provides support for the writers' positions, was a characteristic of the humanities, they were most used in biology to show the importance of relating the current research to the preceding work of other authors in this field.

In another study, Zarei and Mansoori (2007) investigated the metdiscursive patterns across Persian and English languages in applied linguistics and found out that both English and Persian languages emphasized text coherence over interpersonal functions of language. Also, the results revealed that Persian involved more presuppositions in the text, with a great portion of meaning left to be decided by the reader.

Although a general picture of the metadiscourse has been presented in the previous studies, due to the rhetorical importance and also dynamic character of 'metadiscourse' in different disciplines and languages, it seems necessary to scrutinize the issue further. The present study aims to investigate the distribution of metadiscourse in Computer Engineering across Persian and English.

\section{PURPOSE OF STUDY}

Motivated by the fact that meatdiscourse has got an important role to play in academic genre, the present was intended to study metadiscourse in research articles to illuminate the disciplinary distinctions across Persian and English. It is hoped that the results of this study coupled with others would form a strong basis in understanding the language and discipline differences.

\section{CORPUS}

The corpus consisted of one discipline (Computer Engineering) and two languages (English and Persian). The discipline, Computer Engineering, was selected to represent the general stream non-humanities. The articles were selected from well-known, refereed and recently published journals (2004, 2005 \& 2006). In order to investigate different writings, hence balancing out the problem of idiosyncrasy and particularity of writers' styles, the articles were chosen randomly. Articles whose authors were a native speaker of English and Persian were selected for our study. Moreover, at least one author was a native speaker or one of the members of academic staff in U.S or U.K for English articles and a native speaker of Persian for the Persian research articles. A great effort was made to select the articles as diverse in subjects as possible to be able to increase the external validity of the results. The number of the selected articles from the discipline and languages is presented in the following table:

TABLE 1

THE CORPUS USED IN THIS STUDY

\begin{tabular}{|l|l|l|l|}
\hline Language & Discipline & No. of articles & Word count \\
\hline English & Computer Engineering & 5 & 25531 \\
\hline Persian & Computer Engineering & 5 & 26181 \\
\hline Total & $* * * * * * * *$ & 10 & 51712 \\
\hline
\end{tabular}

\section{DATA ANALYSis}

This study used the model of analysis of metadiscourse suggested by Hyland and Tse (2004). This model was used for the purpose since it is designed to specifically capture the underlying principles of academic writing. To this end, Hyland and Tse (2004) claim that metadiscourse needs to be conceptualized as an interpersonal feature of communication, which stands in sharp contrast to Crismore's (1989), and Williams' (1999) views that metadiscourse contributes towards either propositional or interpersonal functions. Furthermore, unlike Mauranen (1993) and Bunton (1999) who see metatext as the writer's self-awareness of text, Hyland and Tse (ibid) believe that 'metadiscourse represents the writer's awareness of the unfolding text as discourse: how writers situate their language use to include a text, a writer and a reader' (p. 167). The intended model, which is presented below, is specifically named 'a model of metadiscourse in academic texts'. 
TABLE 2 .

HYLAND AND TSE (2004) TAXONOMY OF METADISCOURSE

1) Interactive Resources: They help to guide reader through the text:

a) Transitions (T): They express semantic relation between main clauses. Examples: in addition, thus, but, and

b) Frame Markers $(\mathbf{F m})$ : They refer to discourse acts, sequences, or text stages. Examples: finally, to conclude, my purpose here is to

c) Endophoric Markers (En): They refer to information in other parts of the text. Examples: noted above, see figure, in section

d) Evidential Markers (Ev): They refer to sources of information from other texts. Examples: according to X/(Y, 1990)/Z states

e) Code glosses (Co): They help readers grasp functions of ideational material. Examples: namely, e.g., such as, in other words 2) Interactional Resources: They involve the reader in the argument:

a) Hedges (H): They withhold writer's full commitment to proposition. Examples :might, perhaps, possible, about

b) Boosters (Bo): They emphasize force or writer's certainty in proposition. Examples: in fact, definitely, it is clear that

c) Attitude Markers (Am): They express writer's attitude to proposition. Examples: unfortunately, I agree, surprisingly

d) Engagement Markers (En): They explicitly refer to or build relationship with reader. Examples: consider, note that, you can see that

e) Self-mentions (Sm): They explicitly refer to authors. Examples: I, we, my, your

Note: The shortened forms of categories enclosed in parentheses will appear in the analysis

\section{RESULTS AND DISCUSSIONS}

Computer Engineering texts representing non-humanities were carefully analyzed to unravel the nature of disciplinary distinctions in the two different languages. As Table 3 shows, Persian Computer engineering uses interactive resources more than English computer engineering (4.82\% vs. 3.41\%), but English computer engineering uses interactional elements more than Persian Computer engineering (1.4\% vs $1.07 \%$ ). This shows that for Persian comprehensibility of text overrides the relationship that is to be established between the writer and reader. In the same vein, Persian writers' greater use of 'transitions' further supports that the coherence of text is essentially important. Moreover, Engagement markers are also more frequent in English non-humanities, one more time showing the English writers' special attention to the relationship they need to make with the readers.

Also, 'code glosses' appearing in the second position in Persian computer engineering and fifth in English, indicates that Persian writers offer more interpretations of the results. To substantiate their positions, Persian writers provide more 'boosters', that is, they speak out directly about their views, while English writers make their text more documented, and more cautious by making greater use of 'evidentials' and 'hedges'. Though the two disciplines made no specific use of 'frame', 'endophoric', 'attitude markers' and 'self-mentions'(See Table 3), the overall analysis shows that the non-humanities are distinct in both interactive and interactional components of metadiscourse in the two languages.

TABLE 3.

THE USE OF METADISCOURSE IN COMPUTER ENGINEERING ACROSS THE TWO LANGUAGES

\begin{tabular}{|c|c|c|c|c|c|c|c|c|c|c|c|c|c|c|}
\hline \multicolumn{15}{|c|}{ Metadiscourse } \\
\hline \multirow{2}{*}{$\mathrm{L}$} & \multirow[t]{2}{*}{ Dis } & \multirow[t]{2}{*}{ WC } & \multicolumn{6}{|c|}{ Interactive $\%$} & \multicolumn{6}{|c|}{ Interactional \% } \\
\hline & & & $\mathrm{T}$ & Fm & En & Ev & Co & $\mathrm{T}$ & $\mathrm{H}$ & Bo & $\mathrm{Am}$ & Eng & $\mathrm{Sm}$ & $\mathrm{T}$ \\
\hline $\mathrm{P}$ & $\mathrm{CE}$ & 26181 & 1.5 & .8 & .7 & .3 & 1.4 & 4.8 & .2 & .4 & .09 & .01 & .3 & 1.07 \\
\hline $\mathrm{E}$ & $\mathrm{CE}$ & 25531 & .8 & .8 & .7 & .5 & .5 & 3.4 & .5 & .1 & .06 & .2 & .3 & 1.4 \\
\hline $\mathrm{T}$ & **** & 51712 & 2.3 & 1.6 & 1.4 & .8 & 1.9 & 8.2 & .8 & .5 & .1 & .2 & .7 & 2.47 \\
\hline ZT & $* * *$ & $* * * *$ & $7.2 *$ & .1 & 0 & $3 *$ & $7.5^{*}$ & $8^{*}$ & $7.9 *$ & $14^{*}$ & 1.2 & $6.7 *$ & 1.3 & $3.4 *$ \\
\hline
\end{tabular}

Abbreviations: L=Language; P=Persian; E=English; Disc=Discipline; $C E=$ Computer engineering; WC=Word count; T=Total; ZT=Z-Test

\section{CONCLUSION}

The results of this study point to the discipline and community based distinct conventions. Concerning the two languages concerned, the selected Persian articles outweighed their English counterparts, by capitalizing more on metdiscourse elements. Overall, the findings lend support to the idea that languages and disciplines rely on specific use of metadiscourse, making themselves understandable to their readership differently.

Persian proved to put premium on textuality more, relying less on the establishment of relationship with the readers, while English showed comparatively lower reliance on the metadiscursive resources, yet utilizing the interactional side of the metadiscourse slightly more. The discipline specificity uncovers the fact that academic articles demonstrate independent disciplinary visions, i.e., they develop some dynamic rhetorical forms relative to the situations serving to stabilize their experiences and also to the convictions and expectations of discoursal communities seeking to achieve certain academic goals of mutual intelligibility. In other words, the academic writers of different disciplines may be largely subjected to distinct modes of interaction leading to the conceptualization and construction of distinct worlds which are embedded in a particular culture of a particular discoursal community. 
In reference to the distinctiveness of languages it needs to be stated that languages utilize certain linguistic forms and conventions which are encoded by the socio-cultural system of communication (Halliday, 1994). That is, all language use is a social and communicative act in which mutual cooperation and assistance are socio-culturally determined and provided between the producer and receiver of the language to exchange information. And it is through the lenses of the socio-rhetorical framework that some languages produce writer-based prose and some others prefer reader-oriented one (Blagojevic, 2004). In this vein, metadiscourse is not an autonomous stylistic feature of language dissociated from the broader social texture of the two languages, which can be used, reused or left unused at will by the writers. But it is an essential device which can be created out of the societal requirements, which are superordinately determined by the cultural norms of a given language, and subordinately linked to the expectations of a particular professional community. The results go contrary to the idea of the universal scientific discourse propounded by Widdowson (1979). Thus, as a case in point, Persian writers of academic articles addressing English readers, in particular native readers, may need to tone down their overuse of interactive and scale up their underuse of interactional metadiscourse elements in order to arrive at a balanced view of communication based on the target native standards. Therefore, effective writing in different cultures involves a different culture-oriented deployment of resources to represent text and reader (Hyland (2004).

\section{REFERENCES}

[1] Ballard B. \& J. Clanchy. (1991). Assessment by misconception: cultural influences and intellectual traditions in L. HampLyons (eds), Assessing Second Language Writing in Academic Contexts (pp. 19-35). Norwood, NJ: Ablex Pp. 19-35.

[2] Blagojevic S. (2004). Metadiscourse in academic prose: A contrastive study of academic articles written in English by English and Norwegian speakers. Studies about Linguistics 5: 1-7.

[3] Breivega K., D. Dahl \& K. Flottum. (2002). Traces of self and others in research articles. A comparative pilot study of English, French and Norwegian research articles in medicine, economics and linguistics'. International Journal of Applied Linguistics 12(2): 218-239.

[4] Bunton D. (1999). The use of higher level metatext in PhD theses. English for Specific Purposes, 18: 41-56.

[5] Crismore A. (1989). Talking with Readers: Metadiscourse as Rhetorical Act. New York: Peter Lang.

[6] Crismore A. \& R. Farnsworth (1989). Mr. Darwin and his readers: Exploring interpersonal metadiscourse as a dimension of ethos. Rhetoric Review 8 (1): 91-112.

[7] Dahl T. (2004). 'Textual metadiscourse in research articles: A marker of national culture or of academic discipline? Journal of Pragmatics 36: 1807-1825.

[8] Duszak, A. (1994). Academic discourse and intellectual style. Journal of Pragmatics, 21(3), 291-313

[9] Fuertes-Olivera PA, M. Velasco-Sacristan, A. Arribas-Btio \& E. Samaniego-Ferntidez. (2001). Persuasion and advertising English: Metadiscourse in slogans and headlines. Journal of Pragmatics 33: 1291-1307.

[10] Halliday, M. A. K. (1994). An Introduction to Functional Grammar $\left(2^{\text {nd }}\right.$ ed). London: Edward Arnold.

[11] Hinds, J. (1987). Reader versus writer responsibility: a new typology. In: U. Conner, R. Kaplan. (Eds.), Writing Across Languages: Analysis of L2 Texts (pp.141-152). Addison-Wesley, Reading, M.A.

[12] Hyland, K. (1998b). Exploring corporate rhetoric. Metadiscourse in the CEO's letter. Journal of Business Communication 35(2): 224-245.

[13] Hyland, K. (1999). Talking to students: Metadiscourse in introductory coursebooks. English for Specific Purposes 18(1): 3-26.

[14] Hyland, K. (2000). Disciplinary Discourses: Social Interaction in Academic Writing. London: Pearson.

[15] Hyland, K. (2004). Disciplinary interactions: Metadiscourse in L2 postgraduate writing. Journal of Second Language Writing 13: $133-151$.

[16] Hyland, K. \& P. Tse. (2004). Metadiscourse in academic writing: a reappraisal. Applied Linguistics 25 (2): $156-177$.

[17] Johns, A. M. (1997). Text, Role and Context. Developing Academic Literacies. Cambridge: Cambridge University Press.

[18] Mauranen, A. (1993). Contrastive ESP rhetoric: Metatext in Finnish-English economics texts. English for Specific Purposes, $12,3-22$.

[19] Mauranen, A. (2001). Descriptions or explanations? Some methodological issues in contrastive rhetoric. In Hewings, M. (Eds.), Academic writing Context (pp.43-54). University of Birmingham.

[20] Melander, B., J. Swales \& K. Fredrickson. (1997). Journal abstracts from three academic fields in the United States and Sweden: national or disciplinary proclivities? in Duszak A. (eds.), Culture and styles of academic discourse Berlin/ New York: Mounton de Gruyter. Pp. 251-272.

[21] Perez-Llantada, C. (2003). Communication Skills in Academic monologue discourse: empirical and applied Perspective. Circle of Linguistics Applied to Communication/ Círculo de Lingüística Aplicada a la Comunicación.

[22] Schiffrin, D. (1980). Metatalk: Organizational and evaluative brackets in discourse. Sociological Inquiry 50: 199-236.

[23] Ventola, E. \& A. Mauranen. ( 1991). Non-native writing and native revising of scientific articles. In E. Ventola (Eds.), Functional and Systemic Linguistics: Approaches and Uses. Berlin, New York: Mouton de Gruyter.

[24] Valero-Garces, C. (1996). Contrastive ESP rhetoric: Metatext in Spanish-English economics texts. English for Specific Purposes 15( 4): 279-294.

[25] Williams, J. (1989). Style: ten lessons in clarity and grace (5th ed.). Boston: Scott, Foresman.

[26] Widdowson, H. G. (1979). The description in scientific language in H. G. Widdowson (eds), Explorations in Applied linguistics. Oxford: Oxford University Press. Pp.57-61.

[27] Williams, I. A. (1999). Results sections of medical research articles: analysis of rhetorical categories for pedagogical purposes. English for Specific Purposes 18: 347-366.

[28] Zarei, G. R. \& S. Mansoori. (2007). Metadiscourse in academic prose: A contrastive analysis of English and Persian research articles. The Asian ESP Journal, vol.3 (2), 24-40. 
Gholam Reza Zarei received his Ph.D. in Applied Linguistics from Isfahan University, Iran. He is currently teaching different courses at both undergraduate and graduate levels and has published some skill as well as content books and articles.

Sara Mansoori has got an MA in TEFL. She is now teaching English courses at Azad University of Najafabad. 